\title{
Genetic Diversity and Chemical Profile of Rhodophiala bifida Populations from Brazil
}

\author{
Maurício Barancelli Schwedersky ${ }^{1}$ (D) Marina Scopel $^{1}$ (I) $\cdot$ Luciana R. Tallini $^{1,2}$ (D) Jaume Bastida $^{2}$ (D) \\ Tatiana T. Souza-Chies ${ }^{3}$ (D) Nora H. Oleas ${ }^{4}$ (D) - José Angelo Silveira Zuanazzi ${ }^{1}$ (D)
}

Received: 19 November 2019 / Accepted: 25 December 2019 / Published online: 1 May 2020

(C) Sociedade Brasileira de Farmacognosia 2020

\begin{abstract}
Rhodophiala bifida (Herb.) Traub, Amaryllidaceae, is a species native to South America known to produce alkaloids with potential pharmacological uses such as montanine, which has anti-inflammatory potential. R. bifida could be applied as a natural source of montanine. It is important to understand the genetic diversity of this species in order to assess the sustainable use of this plant. The aim of this study was to evaluate the genetic diversity and chemical profiles of the two known natural populations of $R$. bifida in Brazil. This report is the first population genetic study of $R$. bifida. We studied 93 individuals with six Inter-Simple Sequence Repeats (ISSR) primers. A total of 79 loci were amplified. Our results showed high-population structure $(\mathrm{Fst}=0.16)$, with greatest genetic variation at the intrapopulation level. Genetic analyses separated the individuals of $R$. bifida into two clusters that corresponded to each of the natural populations. Chemical profile evaluation was carried out on dried bulbs, leaves, flowers, and flower scapes by liquid chromatography and mass spectrometry. Montanine and nangustine were the main metabolites identified in both populations. These alkaloids concentrations differed by population and by plant part.
\end{abstract}

Keywords Amaryllidaceae alkaloids $\cdot$ Chemical profile $\cdot$ Genetic diversity $\cdot$ ISSR markers $\cdot$ Montanine

\section{Introduction}

Rhodophiala C. Presl, Amaryllidaceae, is a plant genus that phylogenetically belongs to the tribe Hippeastreae, subtribe Hippeastrinae (Meerow et al. 2000). Rhodophiala plants have

Electronic supplementary material The online version of this article (https://doi.org/10.1007/s43450-020-00041-5) contains supplementary material, which is available to authorized users.

José Angelo Silveira Zuanazzi

zuanazzi@ufrgs.br

1 Laboratório de Farmacognosia, Faculdade de Farmácia, Universidade Federal do Rio Grande do Sul, Porto Alegre, RS, Brazil

2 Grupo de Productos Naturales, Facultat de Farmàcia i Ciències de l'Alimentació, Universitat de Barcelona, Barcelona, Spain

3 Departamento de Botânica, Universidade Federal do Rio Grande do Sul, Porto Alegre, RS, Brazil

4 Centro de Investigación de la Biodiversidad y Cambio Climático e Ingeniería en Biodiversidad y Recursos Genéticos, Facultad de Ciencias de Medio Ambiente, Universidad Tecnológica Indoamérica, Machala y Sabanilla, Quito, Ecuador a tunicate bulb $4-6 \mathrm{~cm}$ in diameter, which is set $20-30 \mathrm{~cm}$ underground (Olate and Bridgen 2005). The species of this genus are perennial geophytes with linear leaves less than $1 \mathrm{~cm}$ wide and one to seven zygomorphic funnelform flowers arranged in a scapose pseudo-umbellate inflorescence, with thin pedicels and short-tubed perianth (Meerow and Snijman 1998). Furthermore, these plants present ornamental potential because of their showy flowers (Muñoz et al. 2006).

The species Rhodophiala bifida (Herb.) Traub, Amaryllidaceae, is distributed from Northeast Argentina to Uruguay and Southern Brazil (Olate and Bridgen 2005). In Brazil, only two populations are known, which are in Rio Grande do Sul, the southernmost state of the country (Reflora 2019). This species is known to produce the alkaloid montanine (Wildmann and Brown 1968), a compound with important biological effects such as antimicrobial activity (Castilhos et al. 2007); tumor growth inhibition (Silva et al. 2008); antidepressant, anxiolytic, and anticonvulsant properties; (Silva et al. 2006) and acetylcholinesterase enzyme inhibition (Pagliosa et al. 2010). In the past few years, our research group revealed the biological potential of montanine in autoimmune diseases, such as rheumatoid arthritis (Farinson et al. 2017). In 2015, we obtained a licensed patent regarding the 
Fig. 1 Principal coordinate analysis (PCOA) made from ISSR data for POP1 and POP2 from Rhodophiala bifida

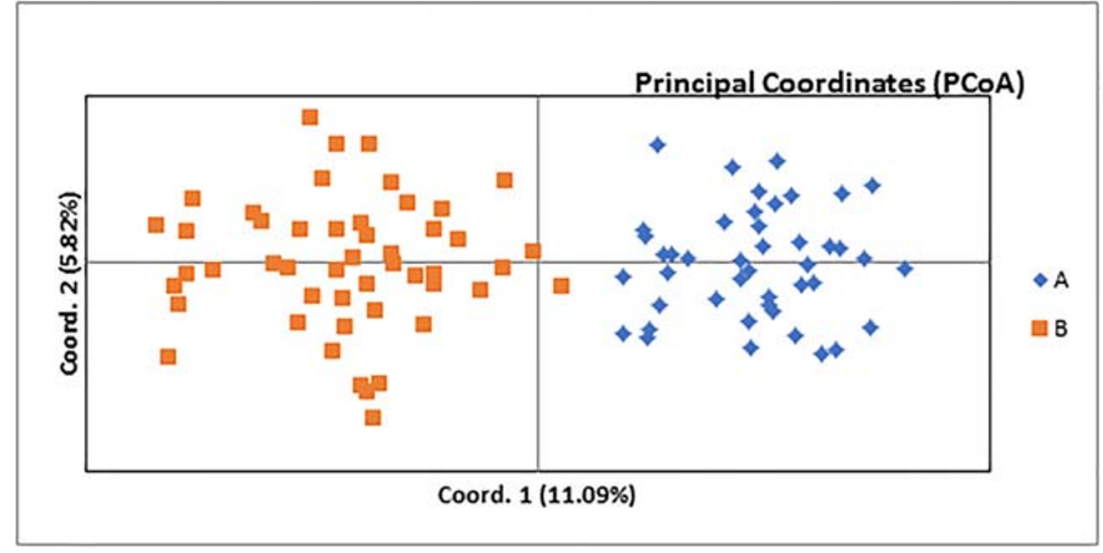

anti-inflammatory potential of montanine and its extraction process from $R$. bifida (De Oliveira et al. 2015). Recently, we also initiated the molecular characterization of two $R$. bifida genes involved in Amaryllidaceae alkaloid biosynthesis and provided new tools to improve montanine production in this species (Reis et al. 2019).

Taking into consideration both the ornamental and medicinal potential of $R$. bifida, the aim of this work was to evaluate the genetic diversity and chemical profile of this species in order to characterize the genetic and chemical profiles of the two known populations of the species in Brazil.

\section{Materials and methods}

Samples of entire plants of Rhodophiala bifida (Herb.) Traub, Amaryllidaceae, were collected in Pelotas, Brazil, and each plant was manually separated into bulbs, leaves, and floral scapes. Voucher specimens of complete individuals from each population (POP1 and POP2) were deposited at ICN Herbarium (Instituto de Biociências, Universidade Federal do Rio Grande do Sul, Porto Alegre, Brazil), with voucher numbers 192333 (POP1) and 184676 (POP2).

A total of 93 individuals were collected: 44 from POP1 and 49 from POP2. Floral scapes were fast-dried in silica gel for DNA isolation. Approximately $50 \mathrm{mg}$ of dried floral scape samples was homogenized using TissueLyser (Qiagen) for $3 \mathrm{~min}$ at $3000 \mathrm{rpm}$. Total genomic DNA extraction was performed following the CTAB (cethyl hexadecyl trimethyl ammonium bromide) method according to Doyle and Doyle (1987), adapted to microcentrifuge tubes. DNA extraction details are described in the Supplementary Material. Six ISSR primers were selected for amplification (see Table S1 in Supplementary Material). Statistical analyses are described in Supplementary Material.

In order to obtain the chemical profile of these samples, all parts of the plant were dried at room temperature and reduced to powder with a knife mill. The alkaloid extracts of these samples were obtained according to the method proposed by Georgieva and co-authors (2007)
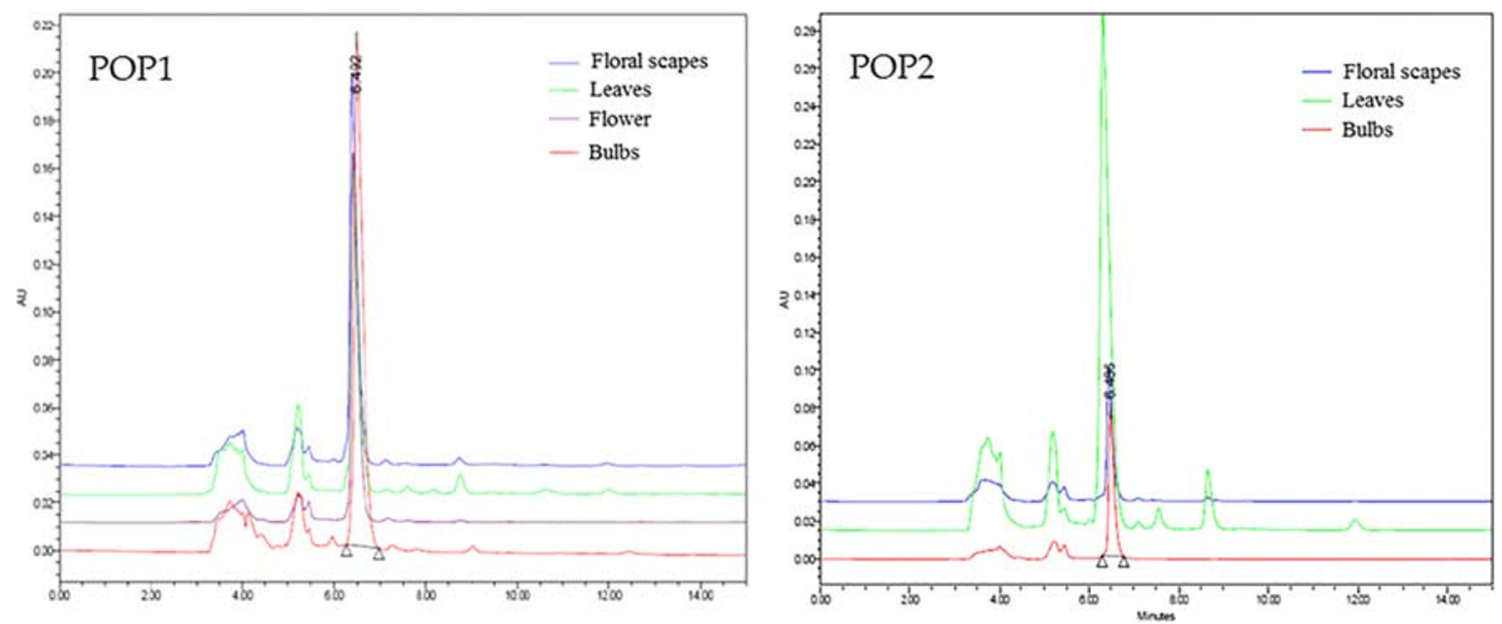

Fig. 2 Chromatogram superposition profile of different organs extracts obtained from POP1 and POP2 by UPLC-DAD at 254 nm. Montanine was identified at 6.492 and $6.495 \mathrm{~min}$ in POP1 and POP2, respectively 
with modifications. The alkaloid extraction process is reported in the Supplementary Material.

The extracts were evaluated by high-performance liquid chromatography (HPLC), Waters Alliance 2695 system, equipped with a diode array detector (DAD), Waters 996. The chromatographic conditions are given in the Supplementary Material. The main alkaloids present in these samples were collected from the HPLC system. The isolated alkaloids were analyzed by Ultra-Performance Liquid Chromatography (UPLC) equipped with a DAD coupled with electrospray ionization (ESI) quadrupole time-of-flight (QTof) mass spectrometry (MS), UPLC-ESI-QTOF-MS (Waters Acquity, USA), operating in positive mode and using $4 \mathrm{kV}$ as impact energy.

\section{Results and discussion}

Amplified ISSR fragments generated an average of 13.1 bands per primer, and the number of amplified bands per primer ranged from six (SP3) to 19 (F13). Fragment sizes varied between 500 and 2080 bp. All six primers resulted in a total of 79 easily distinguishable fragments, for which the percentage of polymorphic loci ranged from 80 to $100 \%$, with a polymorphism mean of $93.3 \%$ (see Table $\mathrm{S} 1$ in Supplementary Material). Other genetic studies in the family are scarce but in general reported a lower mean percentage of polymorphism assessed by ISSR $72.5 \%$ in Phycella australis Ravenna, assessed by ISSR (Flores et al. 2013), and $84.7 \%$ in Narcissus spp. (Jiménez et al. 2009).

We found significant genetic variation $(p<0.001)$ between populations based on Analysis of Molecular Variance (AMOVA). The majority of the total variation $(84.01 \%)$ was found between individuals within the same population, and only $15.99 \%$ of variation was found between populations. This result is consistent with other studies in Amaryllidaceae (e.g., Phycella australis, with $83 \%$ intrapopulation variation, Flores et al. 2013). Population structure (Fst) in R. bifida was 0.16 (see Table S2 in Supplementary Material), indicating a high-population structure despite the relatively short geographic distance between the populations $(1 \mathrm{~km})$, which were located at $31^{\circ} 40^{\prime} 48.5^{\prime \prime} \mathrm{S}, 52^{\circ} 26^{\prime} 44.6^{\prime \prime} \mathrm{W}$ (POP1) and $31^{\circ}$ $40^{\prime} 33.4^{\prime \prime} \mathrm{S}, 52^{\circ} 27^{\prime} 1.3^{\prime \prime} \mathrm{W}$ (POP2). This result shows that gene flow between these populations is relatively low and that gamete exchange preferably occurs between individuals from the same population. The population structure (Fst) of R. bifida is higher than that of other Amaryllidaceae species like Lycoris longituba, with a value of 0.12 (Deng et al. 2006), but it is slightly lower than that of Phycella australis (Fst = 0.17) (Georgieva et al. 2007).

Genetic diversity was slightly higher at POP2 in terms of number of bands, private bands, allele number, and Shannon's information index (see Table S3 in Supplementary Material).
The principal coordinate analysis (PCoA) showed individuals clustered into two different groups that corresponded to the two populations collected (Fig. 1). The first principal component explains $11 \%$ of the observed genetic variation, whereas the second principal component explains almost $6 \%$ of the variation (Fig. 1). Based on the Bayesian analysis provided by STRUCTURE, the most likely number of genetic clusters is $k=2$ (see Fig. S1A in the Supplementary Material). These two groups agree for the most part across the two collected populations (see Fig. S1B in the Supplementary Material or Fig. 2). Genetic variation values found in $R$. bifida suggest that this species uses cross-pollination as its breeding system. Although most of the individuals were assigned to a group corresponding to each geographic population, there were a few individuals, especially in POP2, that were assigned to the other population. This result suggests past and/or current gene flow between the populations, which can be explained by the proximity of the collection sites.

The chemical profiles of the POP1 and POP2 samples were evaluated by HPLC-DAD and UPLC-QTOF-ESI-MS (Fig. 2). Nangustine (1) and montanine (2) were the major peaks observed in all chomatograms Both peaks were isolated and analyzed by mass spectrometry (see Figs. S2 and S3 in the Supplementary Material).

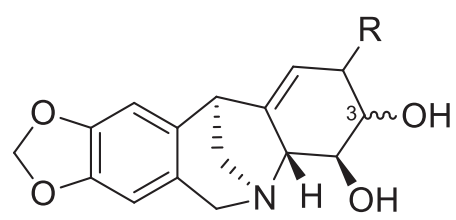

$$
\begin{aligned}
& 13 \alpha-\mathrm{OH} ; \mathrm{R}=\mathrm{H} \\
& 23 \beta-\mathrm{OH} ; \mathrm{R}=\mathrm{OCH}_{3}
\end{aligned}
$$

Compound 1 showed a molecular ion at $m / z[\mathrm{M}+\mathrm{H}]^{+}$ 288.1210 (calculated for $\mathrm{C}_{16} \mathrm{H}_{18} \mathrm{NO}_{4} 288.1199$ ) and fragments $\mathrm{m} / \mathrm{z} 270,241,223$, and 185, characteristic of nangustine alkaloid (Kokas et al. 2008). Compound 2 showed a molecular ion at $\mathrm{m} / \mathrm{z}[\mathrm{M}+\mathrm{H}]^{+} 302.1434$ (calculated for $\mathrm{C}_{17} \mathrm{H}_{20} \mathrm{NO}_{4} 302.1348$ ) and fragments $\mathrm{m} / z 270$, $252,223,185,174$, and 165 , characteristic of montanine alkaloid (Wildmann and Brown 1968; Castilhos et al.
Table 1 Peak area averages of montanine obtained in POP1 and POP2 by UPLC-DAD, $254 \mathrm{~nm}$

\begin{tabular}{lcc}
\hline & POP1 & POP2 \\
\hline Floral scapes & 1817917 & 786275 \\
Leaves & 1556238 & 3857751 \\
Flower & 1365727 & - \\
Bulbs & 2389455 & 740847 \\
Total & 7129337 & 5384873 \\
\hline
\end{tabular}


2007). Compound 2 presented a heterogenic distribution between the plant organs evaluated. According to the information described in Table 1, POP1 presented the highest concentration of compound 2 in bulbs (34\%), followed by floral scapes (25\%), leaves $(22 \%)$, and flowers (19\%), while in POP2, the majority of this alkaloid was detected in leaves $(72 \%)$, followed by bulbs (14\%) and floral scapes (14\%). The quantity found on POP2 flowers was insufficient for extract preparation or an alkaloid determination profile. The high amount of compound 2 found in these extracts is consistent with preliminary investigations carried out by our research group on this species (Castilhos et al. 2007). The presence of this alkaloid, which presents anti-inflammatory activities regarding which pharmaceutical companies have an interest, suggests that $R$. bifida could play an important role in the development of new drugs, increasing its potential market.

Montanine-type alkaloids also were detected in four different Rhodophiala species collected in Chile: $R$. araucana (Phil.) Traub, R. montana (Phil.) Traub, $R$. pratensis (Poepp.) Traub, and $R$. splendens (Renj.) Traub. Among these, the highest level of montanine alkaloid was found in $R$. pratensis extracts (Tallini et al. 2018). A recent publication also described the detection of montanine-type alkaloids in $R$. pratensis (Poepp.) Traub, R. bagnoldii (Herb.) Traub, and R. volckmannii Phil. (Lizama-Bizama et al. 2018). The results obtained in this work and the information described in the literature corroborate the finding that montanine-type alkaloids could be characteristic of the Rhodophiala genus. Taking these results into consideration, $R$. bifida could be an important source of bioactive compounds, including montanine. Our results could become useful for conservation strategies for the sustainable commercial use of this species.

Acknowledgments JASZ and TTSC acknowledge CNPQ for the research fellowship and the National Institute of Science and Technology - INCT BioNat - grant no. 465637/2014-0. LRT and JB (Research Group 2017-SGR-604 from University of Barcelona) are thankful to CCiTUB and Programa Iberoamericano CYTED (Red BIFRENES 416RT0511) for technical and financial support, respectively. LRT is thankful to Coordenação de Pessoal de Nível Superior for a doctoral (Process No. 13553135) and postdoctoral fellowship. BBS thanks EM Stiehl-Alves for all experimental and analytical support in genetic analyses.

Authors' Contributions JASZ and TTS-C conceived of and designed the experiments; MBS performed the experiments and analyzed the data; MS, JB, LRT, and NHO analyzed the data and wrote the paper.

\section{Compliance with Ethical Standards}

Conflict of Interest The authors declare that they have no conflicts of interest.

\section{References}

Castilhos TS, Giordani RB, Henriques AT, Menezes FS, Zuanazzi JAS (2007) Avaliação in vitro das atividades anti-inflamatória, antioxidante e antibacteriana do alcaloide montanina. Rev Bras 17: 209-214. https://doi.org/10.1590/S0102-695X2007000200013

Deng C-L, Zhou J, Gao W-J, Sun F-C, Qin R-Y, Lu L-D (2006) Assessment of genetic diversity of Lycoris longituba (Amaryllidaceae) detected by RAPDs. $J$ Genet 85:205-207. https://doi.org/10.1007/BF02935332

De Oliveira PG, Pedrazza GPR, Farinon M, Xavier RM, Zuanazzi JAS, Spies F (2015) Method for extracting the alkaloid fraction of Rhodophiala bifida (Herb.) Traub. and uses thereof. Estados Unidos, Patente: US2016024074

Doyle JJ, Doyle JL (1987) A rapid DNA isolation procedure for small quantities of fresh leaf tissue. Phytochem Bull 19:11-15

Farinson M, Clarimundo VS, Pedrazza GPR, Gulko OS, Zuanazzi JAS, Xavier RM, De Oliveira PG (2017) Disease modifying antirheumatic activity of the alkaloid montanine on experimental arthritis and fibroblast-like synoviocytes. Eur J Pharmacol 799:180-187. https://doi.org/10.1016/j.ejphar.2017.02.013

Flores C, Delaveau C, Alvarez C, Vergara D, Baeza C, Ruiz E, Uribe M (2013) Genetic variation within three populations of Phycella australis (Phil.) Ravenna from Biobío Region, Chile, evaluated using ISSR markers. Chil J Agric Res 7:77-81. https://doi.org/10. 4067/S0718-58392013000100012

Georgieva L, Berkov S, Kondakova V, Bastida J, Viladomat F, Atanassov A, Codina C (2007) Alkaloid variability in Leucojum aestivum from wild populations. Z Naturforsch C J Biosci 62:627-635. https://doi. org/10.1515/znc-2007-9-1002

Jiménez JF, Sánchez-Gómez P, Guerra J, Molins A, Rosselló JA (2009) Regional speciation or taxonomic inflation? The status of several narrowly distributed and endangered species of Narcissus using ISSR and nuclear ribosomal ITS markers. Folia Geobotanica 44: 145-158. https://doi.org/10.1007/s12224-009-9040-2

Kokas OJ, Banwell MG, Willis AC (2008) Chemoenzymatic approaches to the montanine alkaloids: a total synthesis of (+)nangustine. Tetrahedron 64:6444-6451. https://doi.org/10. 1016/j.tet.2008.04.070

Lizama-Bizama I, Pérez C, Baeza CM, Uriarte E, Becerra J (2018) Alkaloids from Chilean species of the genus Rhodophiala C. Presl (Amaryllidaceae) and their chemotaxonomic importance. Gayana Bot 75:459-465. https://doi.org/10.4067/S 071766432018000100459

Meerow AW, Snijman DA (1998) Flowering plants. Monocotyledons: Lilianae (except Orchidaceae). In: Kubitzki K (ed) The families and genera of vascular plants, vol 3. Springer, Berlin, Germany, $p$ 83-110

Meerow AW, Guy CL, Li Q-B, Yang S-L (2000) Phylogeny of the American Amaryllidaceae based on nrDNA ITS sequences. Syst Bot 25:708-726. https://doi.org/10.2307/2666729

Muñoz M, Riegel R, Seemann P (2006) Use of image cytometry for the early screening of induced autopolyploids. Plant Breed 125:414 416. https://doi.org/10.1111/j.1439-0523.2006.01230.x

Olate E, Bridgen M (2005) Techniques for the in vitro propagation of Rhodophiala and Leucocoryne spp. Acta Hortic 673:335-342. https://doi.org/10.17660/ActaHortic.2005.673.42

Pagliosa LB, Monteiro SC, Silva KB, Andrade JP, Dutilh J, Bastida J, Cammarota M, Zuanazzi JAS (2010) Effect of isoquinoline alkaloids from two Hippeastrum species on in vitro acetylcholinesterase activity. Phytomedicine 7:698-701. https://doi.org/10.1016/j. phymed.2009.10.003

Reflora (2019) Virtual Herbarium. http://reflora.jbrj.gov.br/reflora/ herbarioVirtual/. Accessed 1 July 2019

Reis A, Magne K, Massot S, Tallini LR, Scopel M, Bastida J, Ratet P, Zuanazzi JASZ (2019) Amaryllidaceae alkaloids: identification and 
partial characterization of montanine production in Rhodophiala bifida plant. Sci Rep 9:8471-8481. https://doi.org/10.1038/ s41598-019-44746-7

Silva AFS, De Andrade JP, Bevilaqua LRM, Soza MM, Izquierdo I, Henriques AT, Zuanazzi JAS (2006) Anxiolytic-, antidepressant-, and anticonvulsant-like effects of the alkaloid montanine isolate from Hippeastrum vittatum. Pharmacol Biochem Behav 85:148 154. https://doi.org/10.1016/j.pbb.2006.07.027

Silva AFS, Machado KRB, Rocha AB, Apel MA, Sobral MEG, Henriques AT, Zuanazzi JAS (2008) Screening for cytotoxic activity of extracts and isolated alkaloid from bulbs of Hippeastrum vittatum. Phytomedicine 15:882-885. https://doi.org/10.1016/j. phymed.2007.12.001

Tallini LR, Bastida J, Cortes N, Osorio EH, Theoduloz C, SchmedaHirschmann G (2018) Cholinesterase inhibition activity, alkaloid profiling and molecular docking of Chilean Rhodophiala (Amaryllidaceae). Molecules 23:1532-1558. https://doi.org/10. 3390/molecules23071532

Wildmann WC, Brown CL (1968) Mass spectra of 5,11 methanomorphanthridine alkaloids. The structure of pancracine. J Am Chem Soc 90:64396446. https://doi.org/10.1021/ja01025a036 